\title{
Association of Triglyceride-glucose Index With Intra- and Extra-cranial Arterial Stenosis: a Combined Cross-sectional and Longitudinal Analysis
}

\section{Anxin Wang}

Beijing Tiantan Hospital

\section{Xue Tian}

Capital Medical University

Yingting Zuo

Capital Medical University

\section{Shuohua Chen}

Kailuan General Hospital

\section{Xiaoli Zhang}

Beijing Tiantan Hospital

Jiahuan Guo

Beijing Tiantan Hospital

Shouling Wu ( $\nabla$ drwusl@163.com )

Kailuan General Hospital

\section{Xingquan Zhao}

Beijing Tiantan Hospital

\section{Research Article}

Keywords: Triglyceride-glucose index, Intracranial artery stenosis, Extracranial artery stenosis, Crosssectional analysis, Longitudinal analysis

Posted Date: May 19th, 2021

DOI: https://doi.org/10.21203/rs.3.rs-169479/v2

License: (c) (1) This work is licensed under a Creative Commons Attribution 4.0 International License. Read Full License

Version of Record: A version of this preprint was published at Endocrine on August 4th, 2021. See the published version at https://doi.org/10.1007/s12020-021-02794-y. 


\section{Abstract}

\section{Purpose}

This study aimed to assess the cross-sectional and longitudinal associations of the triglyceride glucose (TyG) index, a simple surrogate marker of insulin resistance, with intra- and extra-cranial artery stenosis (ICAS and ECAS) in Chinese adults.

\section{Methods}

Participants were recruited from the Asymptomatic Polyvascular Abnormalities Community study, 5,381 participants were enrolled in the cross-sectional analysis, then 3,447 and 1,853 participants in the longitudinal analysis for incident ICAS and ECAS, respectively. The TyG index was calculated as In [fasting triglyceride $(\mathrm{mg} / \mathrm{dL}) \times$ fasting glucose $(\mathrm{mg} / \mathrm{dL}) / 2$ ]. Multivariable logistic analysis was used to calculate odds ratio (OR) and $95 \%$ confidence interval $(\mathrm{Cl})$.

\section{Results}

The results of cross-sectional and longitudinal analysis were basically the same, as the fully adjusted OR comparing participants in the highest tertile versus lowest tertile of the TyG index was $1.34(95 \% \mathrm{Cl}, 1.13-$ 1.59) for prevalence of ECAS and $1.85(95 \% \mathrm{Cl}, 1.26-2.71)$ for incident ECAS, respectively. The addition of TyG index to a conventional model had an incremental effect on the predictive value for ECAS. However, we did not observed any significant association between the TyG index and ICAS.

\section{Conclusions}

Elevated TyG index was significantly associated with a higher risk of ECAS, but not with ICAS in Chinese adults. This conclusion lends support to the clinical significant for the TyG index for the assessment of artery stenosis, especially for ECAS.

\section{Introduction}

Atherosclerotic diseases occurring in intracranial artery stenosis (ICAS) and extracranial artery stenosis (ECAS) are the major etiology of ischemic cerebrovascular events, such as stroke and transient ischemic attack. $(1,2)$ It has been reported that ICAS and ECAS separately accounted for approximately $10 \%$ and $15 \%$ of all cerebral ischemic events worldwide, and the proportions were much higher in China than in other populations.(3-5) Therefore, primordial prevention of ischemic vascular diseases through risk factors reduction is fundamental.

Insulin resistance (IR), the critical mechanism of the pathogenesis of diabetes mellitus, has been extensively demonstrated to be significantly related to the development of arterial stiffness and an increased risk of vascular diseases.(6-8) The triglyceride-glucose (TyG) index, which is derived from fasting triglycerides (TGs) and fasting blood glucose (FBG), has been proposed as a simple and 
inexpensive approach to evaluate IR, and has been confirmed to be highly correlated with hyperinsulinaemic-euglycaemic clamp (the gold standard technique for assessing IR).(9-11) Consistent with the findings of $I R$, there is growing evidence to suggest that the TyG index is associated with arterial stiffness (measured by pulse wave velocity) and nephric microvascular damage.(12-15) However, to the best of our knowledge, few study has examined the potential impact of the TyG index on cerebral artery stenosis in Chinese adults.(12) We, therefore, performed this study to determine the cross-sectional and longitudinal associations of the TyG index with ICAS and ECAS in a Chinese community-based study population free of stroke, transient ischemic attack and coronary heart diseases using samples from the Asymptomatic Polyvascular Abnormalities Community (APAC) study.

\section{Materials And Methods}

\section{Study population}

The APAC study is a community-based, prospective, long-term follow-up study to investigate the epidemiology of asymptomatic polyvascular abnormalities in Chinese adults. The detailed of this study design has been published previously. $(16,17)$ In brief, the APAC study included 5440 participants who were aged over or equal to 40 years, free of coronary artery disease, transient ischemic attack, and stroke and follow-up biennially. In the current study, we excluded 59 participants with missing data on TG, FBG and vascular examination results at baseline (2010), leaving 5,381 participants in the cross-sectional analysis. In the longitudinal cohort analysis, we further excluded 712 participants with ICAS at baseline and 1,222 participants without ICAS measurement at 2012, therefore, 3,447 participants were enrolled in the longitudinal cohort study to analysis the association between the TyG index and incident ICAS, similarly, 1,853 participants were enrolled for the analysis of incident ECAS (Figure 1). The study was performed according to the guidelines from the Helsinki Declaration and was approved by the Ethics Committees of the Kailuan General Hospital and the Beijing Tiantan Hospital. Written informed consent was obtained from all participants. Subjects were also informed of abnormal findings and recommended treatment.

\section{Calculation of the TyG index}

Fasting blood samples were collected from the antecubital vein after an 8- to 12-h overnight fast. All the plasma samples were assessed using an auto-analyzer (Hitachi 747, Tokyo, Japan) at the central laboratory of Kailuan Hospital. FBG levels were measured using the hexokinase/glucose-6-phosphate dehydrogenase method with the coefficient of variation using blind quality control specimens $<2.0 \%$. Serum total cholesterol, TG, low-density lipoprotein cholesterol (LDL-C), and high-density lipoprotein cholesterol (HDL-C) levels were measured with the enzymatic colorimetric method. The TyG index was calculated as $\ln [($ fasting TG $(\mathrm{mg} / \mathrm{dl}) \times \mathrm{FBG}(\mathrm{mg} / \mathrm{dl}) / 2] .(18)$

\section{Assessment of ICAS and ECAS}


ICAS was assessed by peak systolic flowing velocity measurements via Transcranial Doppler Ultrasonography, which was performed by two experienced neurologists who were blinded to the baseline information of the participants with portable devices (EME Companion, Nicolet, Madison, WI, USA).(19) The definition of ICAS was according to published criteria $(20,21):>140 \mathrm{~cm} / \mathrm{s}$ for the middle cerebral artery, $>120 \mathrm{~cm} / \mathrm{s}$ for the anterior cerebral artery, $>100 \mathrm{~cm} / \mathrm{s}$ for the posterior cerebral artery and vertebralbasilar, and $>120 \mathrm{~cm} / \mathrm{s}$ for the siphon internal carotid artery. In addition to the above mentioned criteria, the patients' age, the presence of turbulence sound or disturbance in echo frequency, and whether the abnormal velocity was segmental were also taken into account for ICAS diagnosis. Subjects without a good temporal window were considered without stenosis. ICAS was diagnosed if at least one of the studied arteries showed evidence of stenosis or occlusion.

ECAS was defined as the presence of common or extacranial internal carotid artery stenosis or extracranial vertebral artery stenosis. All participants underwent a bilateral carotid duplex ultrasound (Philips iU-22 ultrasound system, Philips Medical Systems, Bothell, WA) in the supine position of structures including the common carotid, internal carotid artery, external carotid artery, vertebral artery and subclavian artery. Both sides of the carotid stenosis were assessed for the presence of ECAS(>0\%), which was graded based on recommendations from the Society of Radiologists in Ultrasound Consensus Conference.(22)

\section{Association of covariates}

Data on other related baseline and medical information were collected via standard questionnaire by trained investigators, including age, sex, smoking status, drinking status, physical activity. Education was classified as illiteracy or primary school, middle school, and high school or above. Income was categorized into $>3000$ and $\leq 3000$ yuan/month. Active physical activity was defined as $\geq 4$ times per week and $\geq 20$ minutes at a time. Smoking and drinking status stratified into never, former or current. Body mass index (BMI) was calculated by dividing body weight $(\mathrm{kg})$ by the square of height $(\mathrm{m})$. Blood pressure was measured in the in the seated position using a mercury sphygmomanometer, and the average of three readings was calculated as systolic blood pressure (SBP) and diastolic blood pressure (DBP). High-sensitivity C-reactive protein (hs-CRP) levels were measured with high-sensitivity particleenhanced immunonephelometry assay. Hypertension was defined as SBP $\geq 140 \mathrm{~mm} \mathrm{Hg}$ or DBP $\geq 90 \mathrm{~mm}$ $\mathrm{Hg}$, any use of antihypertensive drugs, or a self-reported history of hypertension. Diabetes was defined as FBG levels $\geq 7.0 \mathrm{mmol} / \mathrm{L}$, any use of glucose-lowing drugs, or any self-reported history of diabetes. Dyslipidemia was defined as any self-reported history or use of lipid-lowering drugs, or total cholesterol levels $\geq 5.17 \mathrm{mmol} / \mathrm{L}$.

\section{Statistical analysis}

Participants were categorized into three groups according to tertiles of the TyG index. Continuous variables are described as median and interquartile range (IQR) owing the skewed distribution. Categorical variables are described as frequencies and percentages. The Wilcoxon or Kruskal-Wallis test was used to analyze group differences for continuous variables, and the chi-square test was used for 
categorical variables. Multivariable logistic regression models were constructed to assess the association of the TyG index with the outcomes in the cross-sectional and cohort study, by calculating the odds ratios (ORs) and their 95\% confidence intervals (Cls). Model 1 was unadjusted, Model 2 was adjusted for age and sex, Model 3 was further adjusted for BMI, education, income physical activity, smoking status, drinking status, history of hypertension, diabetes, dyslipidemia, antihypertensive agents, antidiabetic agents, lipid-lowering agents, HDL-C, LDL-C, and hs-CRP. P-values for trend were computed using tertiles as ordinal variables. In addition, we also analyzed the effect of the TyG index on the outcomes as a continuous variable using a restricted cubic spline with 5 knots (at the 5th, 25th, 50th, 75th, and 95th percentiles), adjusted for all the covariates above-mentioned.

In addition, we calculated C-statistics, integrated discrimination improvement (IDI) and category-free net reclassification improvement (NRI) to evaluate the incremental predictive value of the TyG index beyond conventional risk factors. Linear regression was used to evaluate the correlation between the TyG index and vascular stenosis risk factors. Furthermore, subgroup analyses according to age ( $<60$ years and $\geq 60$ years), sex, BMI ( $<28$ and $\geq 28 \mathrm{~kg} / \mathrm{m}^{2}$ ), and diabetes (no and yes) were performed to examine the consistence of the effect of a high TyG index on the outcomes, where the interaction of the TyG index with stratified variables was examined by likelihood ratio tests. All analyses were conducted using SAS version 9.4 (SAS Institute Inc., Cary, NC, USA). A two-sided $P<0.05$ was considered statistically significant.

\section{Results}

\section{Baseline characteristics}

In the cross-sectional analysis, a total of 5,381 participants were enrolled, the median age was 52.48 years (IQR, 45.65-61.58), 3219 (59.82\%) were men. The baseline characteristics according to tertiles of the TyG index are presented in Table 1. Compared with participants with the lowest TyG index, participants with higher TyG index were more likely to be men, educated, had higher income, more current smokers, alcohol takers, a higher prevalence of hypertension, diabetes, dyslipidemia, more likely to take antihypertensive agent, antidiabetic agents, and lipid-lowering agents, had a higher level of BMI, SBP, DBP, FBG, TC, TG, HDL-C, LDL-C, and hs-CRP. 
Table 1

Baseline characteristics according to tertiles of the TyG index

\begin{tabular}{|c|c|c|c|c|c|}
\hline \multirow[t]{2}{*}{ Characteristics } & \multirow{2}{*}{$\begin{array}{l}\text { Overall }(n= \\
5381)\end{array}$} & \multicolumn{3}{|c|}{ Tertiles of the TyG index } & \multirow{2}{*}{$\begin{array}{l}P \\
\text { value }\end{array}$} \\
\hline & & $\mathrm{T} 1(<8.38)$ & $\begin{array}{l}\text { T2 (8.39- } \\
8.90)\end{array}$ & $\mathrm{T} 3(\geq 8.91)$ & \\
\hline Age, years & $\begin{array}{l}52.48(45.65- \\
61.58)\end{array}$ & $\begin{array}{l}51.97(45.02- \\
62.07)\end{array}$ & $\begin{array}{l}52.68(45.91- \\
61.96)\end{array}$ & $\begin{array}{l}52.75(46.13- \\
60.83)\end{array}$ & 0.1248 \\
\hline Men, n (\%) & 3219 (59.82) & $998(55.66)$ & $1086(60.54)$ & 1135 (63.27) & $<0.0001$ \\
\hline $\begin{array}{l}\text { High school or } \\
\text { above, n (\%) }\end{array}$ & 2358 (43.82) & 775 (43.22) & $794(44.26)$ & 789 (43.98) & $\begin{array}{l}< \\
0.0001\end{array}$ \\
\hline $\begin{array}{l}\text { Income }>1000 \\
\mathrm{RMB} / \mathrm{m}, \mathrm{n}(\%)\end{array}$ & 4088 (75.97) & $1312(73.17)$ & $1360(75.81)$ & 1416 (78.93) & 0.0003 \\
\hline $\mathrm{BMI}, \mathrm{kg} / \mathrm{m} 2$ & $\begin{array}{l}24.74(22.67- \\
27.04)\end{array}$ & $\begin{array}{l}23.53(21.56- \\
25.71)\end{array}$ & $\begin{array}{l}24.67(22.77- \\
26.83)\end{array}$ & $\begin{array}{l}26.04(23.94- \\
28.08)\end{array}$ & $<0.0001$ \\
\hline \multirow[t]{2}{*}{$\mathrm{SBP}, \mathrm{mm} \mathrm{Hg}$} & 130.00 & 123.33 & 130.00 & 130.67 & \multirow{2}{*}{$\dot{0} 0001$} \\
\hline & $\begin{array}{l}(120.00- \\
140.67)\end{array}$ & $\begin{array}{l}(110.67- \\
140.00)\end{array}$ & $\begin{array}{l}(120.00- \\
141.33)\end{array}$ & $\begin{array}{l}(120.00- \\
146.00)\end{array}$ & \\
\hline DBP, $\mathrm{mm} \mathrm{Hg}$ & $\begin{array}{l}80.67(76.67- \\
90.00)\end{array}$ & $\begin{array}{l}80.00(70.67- \\
88.00)\end{array}$ & $\begin{array}{l}80.67(76.67- \\
90.00)\end{array}$ & $\begin{array}{l}83.67(80.00- \\
90.67)\end{array}$ & $<.0001$ \\
\hline $\begin{array}{l}\text { Current smoker, } \mathrm{n} \\
(\%)\end{array}$ & $1714(31.85)$ & $492(27.44)$ & $560(31.22)$ & $662(36.90)$ & $<.0001$ \\
\hline $\begin{array}{l}\text { Current alcohol use, } \\
\mathrm{n}(\%)\end{array}$ & 1777 (33.02) & $488(27.22)$ & $586(32.66)$ & 703 (39.19) & $<0.0001$ \\
\hline $\begin{array}{l}\text { Active physical } \\
\text { activity, } \mathrm{n}(\%)\end{array}$ & 1856 (34.49) & 634 (35.36) & $626(34.89)$ & 596 (33.22) & 0.1807 \\
\hline Hypertension, n (\%) & $1381(25.66)$ & $294(16.40)$ & $440(24.53)$ & $647(36.06)$ & $<0.0001$ \\
\hline Diabetes, n (\%) & $421(7.82)$ & $42(2.34)$ & $112(6.24)$ & $267(14.88)$ & $<0.0001$ \\
\hline Dyslipidemia, n (\%) & $608(11.30)$ & $82(4.57)$ & $150(8.36)$ & $376(20.96)$ & $<0.0001$ \\
\hline $\begin{array}{l}\text { Antihypertensive } \\
\text { agents, } \mathrm{n}(\%)\end{array}$ & 1045 (19.42) & $225(12.55)$ & $337(18.78)$ & $483(26.92)$ & $<0.0001$ \\
\hline $\begin{array}{l}\text { Antidiabetic agents, } \\
\mathrm{n}(\%)\end{array}$ & $326(6.06)$ & $37(2.06)$ & $79(4.40)$ & $210(11.71)$ & $<.0001$ \\
\hline
\end{tabular}

Abbreviation: BMI, body mass index; DBP, diastolic blood pressure; LDL-C, low-density lipoprotein cholesterol; HDL-C, high-density lipoprotein cholesterol; hs-CRP, high-sensitivity C-reactive protein; SBP, systolic blood pressure; TyG, triglyceride-glucose index 


\begin{tabular}{|c|c|c|c|c|c|}
\hline \multirow[t]{2}{*}{ Characteristics } & \multirow{2}{*}{$\begin{array}{l}\text { Overall }(n= \\
5381)\end{array}$} & \multicolumn{3}{|c|}{ Tertiles of the TyG index } & \multirow{2}{*}{$\begin{array}{l}P \\
\text { value }\end{array}$} \\
\hline & & $\mathrm{T} 1(<8.38)$ & $\begin{array}{l}\text { T2 (8.39- } \\
8.90)\end{array}$ & $\mathrm{T} 3(\geq 8.91)$ & \\
\hline $\begin{array}{l}\text { Lipid-lowering } \\
\text { agents, n (\%) }\end{array}$ & 75 (1.39) & $12(0.67)$ & $21(1.17)$ & $42(2.34)$ & 0.0001 \\
\hline $\begin{array}{l}\text { Fasting blood } \\
\text { glucose, } \mathrm{mmol} / \mathrm{L}\end{array}$ & $\begin{array}{l}5.20(4.82- \\
5.80)\end{array}$ & $\begin{array}{l}4.96(4.61- \\
5.30)\end{array}$ & $\begin{array}{l}5.20(4.84- \\
5.70)\end{array}$ & $\begin{array}{l}5.66(5.12- \\
6.76)\end{array}$ & $\begin{array}{l}< \\
0.0001\end{array}$ \\
\hline $\begin{array}{l}\text { Total cholesterol, } \\
\mathrm{mmol} / \mathrm{L}\end{array}$ & $\begin{array}{l}4.95(4.36- \\
5.63)\end{array}$ & $\begin{array}{l}4.62(4.11- \\
5.21)\end{array}$ & $\begin{array}{l}4.92(4.41- \\
5.55)\end{array}$ & $\begin{array}{l}5.36(4.70- \\
6.04)\end{array}$ & $<.0001$ \\
\hline Triglyceride, $\mathrm{mmol} / \mathrm{L}$ & $\begin{array}{l}1.30(0.93- \\
1.93)\end{array}$ & $\begin{array}{l}0.81(0.65- \\
0.96)\end{array}$ & $\begin{array}{l}1.32(1.17- \\
1.50)\end{array}$ & $\begin{array}{l}2.36(1.91- \\
3.17)\end{array}$ & $\begin{array}{l}< \\
0.0001\end{array}$ \\
\hline $\mathrm{HDL}-\mathrm{C}, \mathrm{mmol} / \mathrm{L}$ & $\begin{array}{l}1.57(1.31- \\
1.90)\end{array}$ & $\begin{array}{l}1.70(1.40- \\
2.01)\end{array}$ & $\begin{array}{l}1.57(1.31- \\
1.86)\end{array}$ & $\begin{array}{l}1.46(1.23- \\
1.78)\end{array}$ & $\dot{0}_{0.0001}$ \\
\hline LDL-C, mmol/L & $\begin{array}{l}2.60(2.16- \\
3.06)\end{array}$ & $\begin{array}{l}2.40(2.02- \\
2.83)\end{array}$ & $\begin{array}{l}2.70(2.30- \\
3.09)\end{array}$ & $\begin{array}{l}2.71(2.21- \\
3.26)\end{array}$ & $\begin{array}{l}< \\
0.0001\end{array}$ \\
\hline $\mathrm{Hs}-\mathrm{CRP}, \mathrm{mg} / \mathrm{dL}$ & $\begin{array}{l}1.00(0.50- \\
2.20)\end{array}$ & $\begin{array}{l}0.78(0.40- \\
1.60)\end{array}$ & $\begin{array}{l}0.90(0.50- \\
2.00)\end{array}$ & $\begin{array}{l}1.40(0.79- \\
2.80)\end{array}$ & $\dot{0}_{0.0001}$ \\
\hline
\end{tabular}

\section{Cross-sectional analysis for the association of the TyG index with prevalent ICAS and ECAS}

Among the 5,381 eligible participants in the cross-sectional analysis, $712(13.23 \%)$ participants were diagnosed of ICAS and 2,843 (52.81\%) were diagnosed of ECAS. The associations of the TyG index with prevalent ICAS and ECAS in the cross-sectional analysis are presented in Table 2. The prevalence of ICAS and ECAS increased with tertiles of the TyG index. In the unadjusted model, the highest tertile of the TyG index was significantly associated with the prevalence of ICAS (OR, 1.44; 95\% Cl, 1.18-1.76; $P$ for trend = $0.0004)$ and ECAS $(\mathrm{OR}, 1.51 ; 95 \% \mathrm{Cl}, 1.32-1.72$; $P$ for trend < 0.0001$)$, compared with the lowest tertile of the TyG index. After fully adjusted for potential covariates, significant association persisted for high TyG index and the prevalence of ECAS $(\mathrm{OR}, 1.34 ; 95 \% \mathrm{Cl}, 1.13-1.59 ; P$ for trend $=0.0009)$, but not for the prevalence of ICAS $(\mathrm{OR}, 1.18 ; 95 \% \mathrm{Cl}, 0.94-1.50 ; P$ for trend $=0.1891)$. Multivariable-adjusted spline regressions showed a J-shaped association between the TyG index and the prevalence of ECAS but not with ICAS (Fig. 2A and 2B). 
Table 2

ORs $(95 \% \mathrm{Cls})$ for the cross-sectional association of the TyG index tertiles with the prevalence of ICAS and ECAS

\begin{tabular}{|c|c|c|c|c|c|}
\hline Outcomes & $\mathrm{T} 1(<8.38)$ & T2 (8.39-8.90) & $\mathrm{T} 3(\geq 8.91)$ & $\begin{array}{l}\text { Per } 1 \text { unit } \\
\text { increase }\end{array}$ & $\begin{array}{l}P \text { for } \\
\text { trend }\end{array}$ \\
\hline \multicolumn{6}{|c|}{ Prevalent ICAS } \\
\hline Case, n (\%) & $190(10.60)$ & $260(14.49)$ & $262(14.60)$ & & \\
\hline Model 1 & Reference & $\begin{array}{l}1.43(1.17- \\
1.75)\end{array}$ & $\begin{array}{l}1.44(1.18- \\
1.76)\end{array}$ & $1.24(1.10-1.39)$ & 0.0004 \\
\hline Model 2 & Reference & $\begin{array}{l}1.45(1.19- \\
1.78)\end{array}$ & $\begin{array}{l}1.54(1.25- \\
1.88)\end{array}$ & $1.31(1.16-1.48)$ & $<0.0001$ \\
\hline Model 3 & Reference & $\begin{array}{l}1.29(1.04- \\
1.60)\end{array}$ & $\begin{array}{l}1.18(0.94- \\
1.50)\end{array}$ & $1.10(0.95-1.28)$ & 0.1891 \\
\hline \multicolumn{6}{|l|}{$\begin{array}{l}\text { Prevalent } \\
\text { ECAS }\end{array}$} \\
\hline Case, n (\%) & $833(46.46)$ & $993(55.35)$ & 1017(56.69) & & \\
\hline Model 1 & Reference & $\begin{array}{l}1.43(1.25- \\
1.63)\end{array}$ & $\begin{array}{l}1.51(1.32- \\
1.72)\end{array}$ & $1.31(1.21-1.43)$ & $<0.0001$ \\
\hline Model 2 & Reference & $\begin{array}{l}1.47(1.26- \\
1.71)\end{array}$ & $\begin{array}{l}1.58(1.36- \\
1.84)\end{array}$ & $1.35(1.23-1.48)$ & $<0.0001$ \\
\hline Model 3 & Reference & $\begin{array}{l}1.34(1.15- \\
1.58)\end{array}$ & $\begin{array}{l}1.34(1.13- \\
1.59)\end{array}$ & $1.22(1.09-1.36)$ & 0.0009 \\
\hline \multicolumn{6}{|c|}{$\begin{array}{l}\text { Abbreviations: Cl, confidence interval; ECAS, extracranial carotid stenosis; ICAS, intracranial arterial } \\
\text { stenosis; OR, odds ratio; TyG, triglyceride-glucose index }\end{array}$} \\
\hline \multicolumn{6}{|c|}{ Model 1: unadjusted } \\
\hline \multicolumn{6}{|c|}{ Model 2. adjusted for age and sex } \\
\hline \multicolumn{6}{|c|}{$\begin{array}{l}\text { Model 3: further adjusted for body mass index, education, income, physical activity, smoking status, } \\
\text { drinking status, history of hypertension, diabetes, dyslipidemia, antihypertensive agents, antidiabetic } \\
\text { agents, lipid-lowering agents, high-density lipoprotein cholesterol, low-density lipoprotein cholesterol, } \\
\text { high-sensitivity C-reactive protein. }\end{array}$} \\
\hline
\end{tabular}

\section{Longitudinal analysis for the association of the TyG index with incident ICAS and ECAS}

In the longitudinal analysis, 351 (10.18\%) incident ICAS and 234 (12.63\%) incident ECAS were diagnosed. The associations of the TyG index with incident ICAS and ECAS in the longitudinal cohort analysis are presented in Table 3. The highest tertile of the TyG index was associated with a 1.85-fold higher risk for incidence of ECAS $(\mathrm{OR}, 1.85 ; 95 \% \mathrm{Cl}, 1.26-2.71$; $P$ for trend $=0.0007)$ in the fully adjusted model, compared with the lowest tertile of the TyG index. Whereas the association between TyG index and 
incident ICAS was not statistically significant (OR, 1.02; $95 \% \mathrm{Cl}, 0.74-1.40, P$ for trend $=0.8777)$. Multivariable-adjusted spline regression showed the similar trend association (Fig. $2 \mathrm{C}$ and 2D).

Table 3

ORs ( $95 \% \mathrm{Cls}$ ) for the longitudinal association of the TyG index tertiles with incident ICAS and ECAS

\begin{tabular}{|c|c|c|c|c|c|}
\hline Outcomes & $\begin{array}{l}\text { T1 (< } \\
8.38)\end{array}$ & T2 (8.39-8.90) & $\mathrm{T} 3(\geq 8.91)$ & $\begin{array}{l}\text { Per } 1 \text { unit } \\
\text { increase }\end{array}$ & $\begin{array}{l}P \text { for } \\
\text { trend }\end{array}$ \\
\hline \multicolumn{6}{|c|}{ Incident ICAS } \\
\hline Case, n (\%) & $113(9.38)$ & $120(10.64)$ & 118(10.59) & & \\
\hline Model 1 & Reference & $\begin{array}{l}1.15(0.88- \\
1.51)\end{array}$ & $\begin{array}{l}1.14(0.87- \\
1.50)\end{array}$ & $1.03(0.87-1.22)$ & 0.3273 \\
\hline Model 2 & Reference & $\begin{array}{l}1.18(0.90- \\
1.55)\end{array}$ & $\begin{array}{l}1.19(0.90- \\
1.57)\end{array}$ & $1.07(0.90-1.26)$ & 0.2106 \\
\hline Model 3 & Reference & $\begin{array}{l}1.12(0.84- \\
1.49)\end{array}$ & $\begin{array}{l}1.02(0.74- \\
1.40)\end{array}$ & $1.01(0.78-1.17)$ & 0.8777 \\
\hline \multicolumn{6}{|l|}{$\begin{array}{l}\text { Incident } \\
\text { ECAS }\end{array}$} \\
\hline Case, n (\%) & $68(9.43)$ & 63(11.09) & 103(18.26) & & \\
\hline Model 1 & Reference & $\begin{array}{l}1.20(0.83- \\
1.72)\end{array}$ & $\begin{array}{l}2.15(1.54- \\
2.98)\end{array}$ & $1.55(1.27-1.89)$ & $<0.0001$ \\
\hline Model 2 & Reference & $\begin{array}{l}1.10(0.76- \\
1.59)\end{array}$ & $\begin{array}{l}1.92(1.37- \\
2.69)\end{array}$ & $1.45(1.18-1.78)$ & 0.0001 \\
\hline Model 3 & Reference & $\begin{array}{l}1.23(0.83- \\
1.81)\end{array}$ & $\begin{array}{l}1.85(1.26- \\
2.71)\end{array}$ & $1.38(1.09-1.75)$ & 0.0007 \\
\hline
\end{tabular}

Abbreviations: $\mathrm{Cl}$, confidence interval; ECAS, extracranial carotid stenosis; ICAS, intracranial arterial stenosis; OR, odds ratio; TyG, triglyceride-glucose index

Model 1: unadjusted

Model 2. adjusted for age and sex

Model 3: further adjusted for body mass index, education, income, physical activity, smoking status, drinking status, history of hypertension, diabetes, dyslipidemia, antihypertensive agents, antidiabetic agents, lipid-lowering agents, high-density lipoprotein cholesterol, low-density lipoprotein cholesterol, high-sensitivity C-reactive protein.

\section{Correlation between the TyG index and vascular stenosis risk factors}

The linear regression was performed to determine the correlation between the TyG index stenosis risk factors. Results showed that the TyG index was positively correlated with sex (men), BMI, DBP, DBP, FBG, 
TC, TG, LDL-C, and hs-CRP, while negatively correlated with HDL-C and no significant correlation with age (Table S1).

\section{Incremental predictive value of the TyG index}

We evaluated whether the TyG index could further increase the predictive value of conventional risk factors (Table 4). In the cross-sectional analysis, for prevalent ICAS as the outcome of interest, the Cstatistic, IDI and NRI did not significant improve with the addition of the TyG index. When prevalent ECAS was taken as the outcome of interest, although the $\mathrm{C}$-statistics by the conventional model did not significantly improve with the addition of the TyG index (from 0.797 to $0.798, P=0.0881$ ), the discriminatory power and reclassification ability appeared to be substantially improved (IDI, $0.20 \%, P=$ 0.0011 ; category-free NRI 9.14\%, $P=0.0008)$. Similar results were found in the longitudinal cohort analysis. 
Table 4

Reclassification and discrimination statistics for outcomes by the TyG index

C-statistic

Estimate $(95 \%$

$\mathrm{Cl})$
IDI

$P$ value
Estimate

$(95 \% \mathrm{Cl}), \%$

Category-free NRI

\begin{tabular}{|c|c|c|c|c|c|c|}
\hline & $\begin{array}{l}\text { Estimate }(95 \% \\
\mathrm{Cl})\end{array}$ & $\begin{array}{l}\mathrm{P} \\
\text { value }\end{array}$ & $\begin{array}{l}\text { Estimate } \\
(95 \% \mathrm{Cl}), \%\end{array}$ & $\begin{array}{l}\mathrm{P} \\
\text { value }\end{array}$ & $\begin{array}{l}\text { Estimate } \\
(95 \% \mathrm{Cl}), \%\end{array}$ & $\begin{array}{l}\mathrm{P} \\
\text { value }\end{array}$ \\
\hline \multicolumn{7}{|l|}{ Prevalent ICAS } \\
\hline Convention model & $\begin{array}{l}0.727(0.701- \\
0.748)\end{array}$ & & Reference & & Reference & \\
\hline $\begin{array}{l}\text { Convention model } \\
+ \text { TyG index }\end{array}$ & $\begin{array}{l}0.728(0.707- \\
0.748)\end{array}$ & 0.7431 & $\begin{array}{l}0.03(-0.03- \\
0.10)\end{array}$ & 0.3246 & $\begin{array}{l}4.67(-3.19- \\
12.54)\end{array}$ & 0.2453 \\
\hline \multicolumn{7}{|l|}{ Prevalent ECAS } \\
\hline Convention model & $\begin{array}{l}0.797(0.785- \\
0.809)\end{array}$ & & Reference & & Reference & \\
\hline $\begin{array}{l}\text { Convention model } \\
+ \text { TyG index }\end{array}$ & $\begin{array}{l}0.798(0.786- \\
0.810)\end{array}$ & 0.0881 & $\begin{array}{l}0.20(0.08- \\
0.32)\end{array}$ & 0.0011 & $\begin{array}{l}9.14(3.83- \\
14.46)\end{array}$ & 0.0008 \\
\hline \multicolumn{7}{|l|}{ Incident ICAS } \\
\hline Convention model & $\begin{array}{l}0.657(0.626- \\
0.688)\end{array}$ & & Reference & & Reference & \\
\hline $\begin{array}{l}\text { Convention model } \\
+ \text { TyG index }\end{array}$ & $\begin{array}{l}0.657(0.626- \\
0.688)\end{array}$ & 0.9006 & $\begin{array}{l}0.009(-0.002- \\
0.04)\end{array}$ & 0.5282 & $\begin{array}{l}2.07(-13.09- \\
8.96)\end{array}$ & 0.7134 \\
\hline \multicolumn{7}{|l|}{ Incident ECAS } \\
\hline Convention model & $\begin{array}{l}0.722(0.688- \\
0.756)\end{array}$ & & Reference & & Reference & \\
\hline $\begin{array}{l}\text { Convention model } \\
+ \text { TyG index }\end{array}$ & $\begin{array}{l}0.732(0.699- \\
0.765)\end{array}$ & 0.0308 & $\begin{array}{l}0.30(0.01- \\
0.68)\end{array}$ & 0.0315 & $\begin{array}{l}20.03(6.36- \\
33.71)\end{array}$ & 0.0042 \\
\hline
\end{tabular}

Abbreviations: ECAS, extracranial carotid stenosis; ICAS, intracranial arterial stenosis; IDI, integrated discrimination index; NRI, net reclassification index; TyG, triglyceride-glucose index.

Adjusted for age, sex, body mass index, education, income, physical activity, smoking status, drinking status, history of hypertension, diabetes, dyslipidemia, antihypertensive agents, antidiabetic agents, lipid-lowering agents, high-density lipoprotein cholesterol, low-density lipoprotein cholesterol, highsensitivity C-reactive protein, and lipid-lowering agents.

\section{Subgroup analyses}

Results of subgroup analyses are shown in Table S2. The association of a high TyG index with ICAS and ECAS in the cross-sectional and longitudinal study were generally consistent across different subgroups. There was no significant interaction between the TyG index and these stratified covariates ( $P$ for interaction $>0.05$ for all). 


\section{Discussion}

In this study, we identified a significant association of the TyG index with ECAS in both cross-sectional and longitudinal cohort analysis. The addition of the TyG index to the conventional models significantly promoted the ability of risk stratification. However, the TyG index failed to show any statistical significance on ICAS in the present analysis. The trend remained robust among the stratified analyses. Our study suggests that the TyG index, as a marker of IR, may help identify subjects at high risk of artery stenosis, especially for ECAS.

A few reports have investigated the relationship between IR and ICAS. The Barcelona-Asymptomatic Intracranial Atherosclerosis (AsIA) study including 933 Caucasian subjects aged $>50$ years showed that IR emerged as an important molecular pathway involved in the development of intracranial atherosclerotic disease from its asymptomatic stage.(23) A Korean study of 110 participants showed that IR was associated with intracranial atherosclerosis in patients with ischemic stroke without diabetes. (24) Similar, a Chinese cross-sectional study including 2007 participants aged over 40 years showed IR predicted the prevalence of asymptomatic ICAS in men, however, the history of hypertension, diabetes, dyslipidemia and medications on these diseases were not been taken into account, the results may should be explained with caution.(25) In these studies, IR was evaluated using the homeostatic model assessment technique index (HOMA-IR), which is calculated by fating insulin and glucose. However, the insulin concentrations are not routinely measured in clinical practice, leading to an HOMA-IR that is inappropriate for clinical practice on a large scale. By contrast, the TyG index can be done from a standard blood profile at no extra cost, and the TyG index is well related to the hyperinsulinemiceuglycemic clamp and HOMA-IR, it is therefore widely available in recent studies. $(26,27)$ However, up to date, the evidence on whether the TyG index can serve as an independent predictor of ICAS remained unclear. To address this knowledge gap, we conducted the current study, our findings show that in both cross-sectional and longitudinal analysis, the TyG index failed to show any statistical significance on ICAS in the APAC study. The inconsistent results between our study and above-mentioned may be attributed to the design, study population and the measurement in determining atherosclerosis.

To our knowledge, there was limited evidence regarding the relationship between the TyG index and ECAS in Asians up to date, partly because the phenomenon that the prevalence of ECAS is more common in Caucasians than in Asians.(28) The AsIA study showed that patients with diabetes mellitus had a higher OR for moderate-severe ECAS than ICAS.(23) Another study in Caucasians showed that the TyG index was significantly associated with carotid atherosclerosis.(13) In contrast, one Chinese cross-sectional study have investigated the correlation of the TyG index with carotid stenosis, the results showed there was no significant association of TyG index with the carotid hypertrophy and carotid plaque.(12) The inconsistency may be explained by ethnic differences of the study population. Results from our study demonstrated that elevated TyG index was significantly associated with ECAS in Chinese patients without stroke, transient ischemic stroke and coronary heart diseases. The TyG index actually plays an important role in the progression of atherosclerosis, our study suggested that those with high TyG index warrant particular vigilance for the future risk of ECAS. 
The mechanisms for the different association of the TyG index with ICAS and ECAS were unclear, while several hypotheses have been proposed. First, IR predisposes to several disorders such as hyperglycemia, hypertension, and dyslipidemia. Previous studies showed that there were some differences in risk factors between ICAS and ECAS. A meta-analysis consisted of 15 studies in Asians showed that there was no significant difference between ICAS and ECAS in terms of age, hypertension and diabetes,(29) while this meta-analysis together with several other studies revealed that dyslipidemia was more closely associated with ECAS than with ICAS.(29-31) In our study, we found that the prevalence of dyslipidemia in the highest tertile group was more than 5 -fold higher than that in the lowest tertile group. Circulating biomarkers may represent a powerful tool to assess the pathophysiology of atherosclerosis in vivo, our study also showed that the TC, TG, LDL-C and hs-CRP was positively correlated to the TyG index. The high prevalence of dyslipidemia and high levels of blood markers may contribute to the pathway between high TyG index and ECAS in our analysis, similarly to previous reports. $(23,32,33)$ Second, IR not only plays an important role on atherogenesis, but also in advanced plaque progression by promoting apoptosis of macrophages, endothelial cells, and vascular smooth muscle cells, the TyG index reflects IR in the muscle thus may better reflect peripheral insulin resistance. The TyG index has been reported to be associated with carotid and coronary atherosclerosis,(34) which is also more correlated with ECAS. The precise mechanisms for the discrepancy relationship of the TyG index with ICAS and ECAS needed further investigations to clarify.

The strength of this study is its combined cross-sectional and longitudinal aspects. Nevertheless, there are several limitations to the present study. Firstly, the study relies on TCD for the diagnosis, which is partly operator-dependent and unable to accurately determine the extent of vascular stenosis. However, non-invasive TCD is a safer, more accessible, and less expensive method of evaluating intracranial circulation than invasive catheter angiography. Second, due to the shortage of records on insulin, we could not compare the TyG index with HOMA-IR and the hyperinsulinemic-euglycemic clamp test. Third, we chose asymptomatic ICAS and ECAS as parameters to evaluate atherosclerosis. Causes of stenosis other than atherosclerosis (e.g. vasculitis, artery dissection) were not evaluated in the study.

\section{Conclusions}

In our study, an independent association between elevated TyG index and ECAS was seen regardless of other conventional vascular risk factors, while the TyG index failed to show a statistically significance on ICAS. The TyG index, as simple marker of IR, might be an important predictor of artery stenosis, reflecting vascular risk, especially for ECAS. Further prospective large-scale studies will be needed to elucidate the exact mechanism of the relationship between the TyG index and atherosclerotic stenosis.

\section{Declarations}

\section{Funding}


This work was supported by Chinese Academy of Medical Sciences Innovation Fund for Medical Sciences (2019-I2M-5-029), Beijing Municipal Committee of Science and Technology (Z201100005620010), Beijing Natural Science Foundation (Z200016), Young Elite Scientists Sponsorship Program by CAST (2018QNRC001), Beijing Municipal Administration of Hospitals Incubating Program (PX2020021), and Beijing Excellent Talents Training Program (2018000021469G234).

\section{Conflicts of Interest}

The authors have no conflicts of interest to declare.

\section{Availability of data and code}

Data are available to researchers on request for purposes of reproducing the results or replicating the procedure by directly contacting the corresponding author.

\section{Authors' contributions}

AW and XT made substantial contributions to study design, data collection, data analysis and manuscript writing. SW and XZ (Xingquan Zhao) made substantial contributions to study design and intellectual direction. YZ, SC, XZ (Xiaoli Zhang), and JG made contributions to data collection. All authors read and approved the final manuscript.

\section{Ethics approval and consent to participate}

The study was performed according to the guidelines of the Helsinki Declaration and was approved by the Ethics Committee of Kailuan General Hospital (approval number: 2006-05) and Beijing Tiantan Hospital (approval number: 2010-014-01). All participants were agreed to take part in the study and provided informed written consent.

\section{Consent for publication}

Not applicable.

\section{Acknowledgments}

We thank all the participants of the APAC study for their invaluable contributions.

\section{References}

1. Wang Y, Zhao X, Liu L, Soo YO, Pu Y, Pan Y, Wang Y, Zou X, Leung TW, Cai Y, Bai Q, Wu Y, Wang C, Pan $X$, Luo B, Wong KS. Prevalence and outcomes of symptomatic intracranial large artery stenoses and occlusions in China: the Chinese Intracranial Atherosclerosis (CICAS) Study. Stroke. 2014;45(3):663669. 
2. Xu Y, Yuan C, Zhou Z, He L, Mi D, Li R, Cui Y, Wang Y, Wang Y, Liu G, Zheng Z, Zhao X. Co-existing intracranial and extracranial carotid artery atherosclerotic plaques and recurrent stroke risk: a threedimensional multicontrast cardiovascular magnetic resonance study. J Cardiovasc Magn Reson. 2016;18(1):90.

3. Siddiq F, Chaudhry SA, Vazquez G, Suri MF, Qureshi Al. Intracranial stenosis in young patients: unique characteristics and risk factors. Neuroepidemiology. 2012;38(3):148-153.

4. Segura T, Serena J, Castellanos M, Teruel J, Vilar C, Dávalos A. Embolism in acute middle cerebral artery stenosis. Neurology. 2001;56(4):497-501.

5. Kolominsky-Rabas PL, Weber M, Gefeller O, Neundoerfer B, Heuschmann PU. Epidemiology of ischemic stroke subtypes according to TOAST criteria: incidence, recurrence, and long-term survival in ischemic stroke subtypes: a population-based study. Stroke. 2001;32(12):2735-2740.

6. Urbina EM, Gao Z, Khoury PR, Martin LJ, Dolan LM. Insulin resistance and arterial stiffness in healthy adolescents and young adults. Diabetologia. 2012;55(3):625-631.

7. Korkmaz H, Sozen M, Kebapcilar L. Increased arterial stiffness and its relationship with inflammation, insulin, and insulin resistance in celiac disease. Eur J Gastroenterol Hepatol. 2015;27(10):1193-1199.

8. Iguchi T, Hasegawa T, Otsuka K, Matsumoto K, Yamazaki T, Nishimura S, Nakata S, Ehara S, Kataoka T, Shimada K, Yoshiyama M. Insulin resistance is associated with coronary plaque vulnerability: insight from optical coherence tomography analysis. Eur Heart J Cardiovasc Imaging. 2014;15(3):284-291.

9. Guerrero-Romero F, Simental-Mendía LE, González-Ortiz M, Martínez-Abundis E, Ramos-Zavala MG, Hernández-González SO, Jacques-Camarena 0 , Rodríguez-Morán M. The product of triglycerides and glucose, a simple measure of insulin sensitivity. Comparison with the euglycemic-hyperinsulinemic clamp. J Clin Endocrinol Metab. 2010;95(7):3347-3351.

10. Du T, Yuan G, Zhang M, Zhou X, Sun X, Yu X. Clinical usefulness of lipid ratios, visceral adiposity indicators, and the triglycerides and glucose index as risk markers of insulin resistance. Cardiovasc Diabetol. 2014;13:146.

11. Zhao Q, Zhang TY, Cheng YJ, Ma Y, Xu YK, Yang JQ, Zhou YJ. Impacts of triglyceride-glucose index on prognosis of patients with type 2 diabetes mellitus and non-ST-segment elevation acute coronary syndrome: results from an observational cohort study in China. Cardiovasc Diabetol. 2020;19(1):108.

12. Zhao S, Yu S, Chi C, Fan X, Tang J, Ji H, Teliewubai J, Zhang Y, Xu Y. Association between macroand microvascular damage and the triglyceride glucose index in community-dwelling elderly individuals: the Northern Shanghai Study. Cardiovasc Diabetol. 2019;18(1):95.

13. Irace C, Carallo C, Scavelli FB, De Franceschi MS, Esposito T, Tripolino C, Gnasso A. Markers of insulin resistance and carotid atherosclerosis. A comparison of the homeostasis model assessment and triglyceride glucose index. Int J Clin Pract. 2013;67(7):665-672.

14. Lee SB, Ahn CW, Lee BK, Kang S, Nam JS, You JH, Kim MJ, Kim MK, Park JS. Association between triglyceride glucose index and arterial stiffness in Korean adults. Cardiovasc Diabetol. 2018;17(1):41. 
15. Park K, Ahn CW, Lee SB, Kang S, Nam JS, Lee BK, Kim JH, Park JS. Elevated TyG Index Predicts Progression of Coronary Artery Calcification. Diabetes Care. 2019;42(8):1569-1573.

16. Zhou Y, Li Y, Xu L, Xu J, Wang A, Gao X, Wu S, Wei WB, Zhao X, Jonas JB. Asymptomatic polyvascular abnormalities in community (APAC) study in China: objectives, design and baseline characteristics. PLoS One. 2013;8(12):e84685.

17. Wang J, Wu J, Zhang S, Zhang L, Wang C, Gao X, Zhou Y, Wang A, Wu S, Zhao X. Elevated fasting glucose as a potential predictor for asymptomatic cerebral artery stenosis: a cross-sectional study in Chinese adults. Atherosclerosis. 2014;237(2):661-665.

18. Ma X, Dong L, Shao Q, Cheng Y, Lv S, Sun Y, Shen H, Wang Z, Zhou Y, Liu X. Triglyceride glucose index for predicting cardiovascular outcomes after percutaneous coronary intervention in patients with type 2 diabetes mellitus and acute coronary syndrome. Cardiovasc Diabetol. 2020;19(1):31.

19. Babikian VL, Feldmann E, Wechsler LR, Newell DW, Gomez CR, Bogdahn U, Caplan LR, Spencer MP, Tegeler C, Ringelstein EB, Alexandrov AV. Transcranial Doppler ultrasonography: year 2000 update. J Neuroimaging. 2000;10(2):101-115.

20. Meseguer E, Lavallée PC, Mazighi M, Labreuche J, Cabrejo L, Olivot JM, Abboud H, Slaoui T, Lapergue B, Guidoux C, Klein IF, Touboul PJ, Amarenco P. Yield of systematic transcranial Doppler in patients with transient ischemic attack. Ann Neurol. 2010;68(1):9-17.

21. Wong KS, Huang YN, Yang HB, Gao S, Li H, Liu JY, Liu Y, Tang A. A door-to-door survey of intracranial atherosclerosis in Liangbei County, China. Neurology. 2007;68(23):2031-2034.

22. Grant E, Benson C, Moneta G, Alexandrov A, Baker J, Bluth E, Carroll B, Eliasziw M, Gocke J, Hertzberg B, Katanick S, Needleman L, Pellerito J, Polak J, Rholl K, Wooster D, Zierler R. Carotid artery stenosis: gray-scale and Doppler US diagnosis--Society of Radiologists in Ultrasound Consensus Conference. Radiology. 2003;229(2):340-346.

23. López-Cancio $E$, Galán A, Dorado L, Jiménez $M$, Hernández $M$, Millán $M$, Reverté $S$, Suñol $A$, Barallat J, Massuet A, Alzamora M, Dávalos A, Arenillas J. Biological signatures of asymptomatic extra- and intracranial atherosclerosis: the Barcelona-AsIA (Asymptomatic Intracranial Atherosclerosis) study. Stroke. 2012;43(10):2712-2719.

24. Park H, Kyeong-Ho, Park D, Lee H, Chang H, Kim Y, Cho K. Correlation between insulin resistance and intracranial atherosclerosis in patients with ischemic stroke without diabetes. Journal of stroke and cerebrovascular diseases : the official journal of National Stroke Association. 2008;17(6):401-405.

25. Wang Q, Zhao Y, Wang X, Ji X, Sang S, Shao S, Ma X, Wang G, Lv M, Xue F, Du Y, Sun Q. Association between asymptomatic intracranial arterial stenosis and insulin resistance or diabetes mellitus: a cross-sectional study in rural Shandong, China. BMJ open diabetes research \& care. 2020;8(2).

26. Sánchez-García A, Rodríguez-Gutiérrez R, Mancillas-Adame L, González-Nava V, Díaz GonzálezColmenero A, Solis RC, Álvarez-Villalobos NA, González-González JG. Diagnostic Accuracy of the Triglyceride and Glucose Index for Insulin Resistance: A Systematic Review. Int J Endocrinol. 2020;2020:4678526. 
27. Simental-Mendía LE, Rodríguez-Morán M, Guerrero-Romero F. The product of fasting glucose and triglycerides as surrogate for identifying insulin resistance in apparently healthy subjects. Metab Syndr Relat Disord. 2008;6(4):299-304.

28. Kim J, Nah H, Park S, Kim S, Cho K, Lee J, Lee Y, Kim J, Ha S, Kim E, Kim D, Kang D, Kwon S, Yu K, Lee B. Risk factors and stroke mechanisms in atherosclerotic stroke: intracranial compared with extracranial and anterior compared with posterior circulation disease. Stroke. 2012;43(12):33133318.

29. Ding X, Li C, Yu K, Gao A, Xiao L, Peng F, Wang J, Chen L, Wu Y. Different risk factors between intracranial and extracranial atherosclerotic stenosis in Asian population: a systematic review and meta-analysis. The International journal of neuroscience. 2014;124(11):834-840.

30. Kim JS, Nah HW, Park SM, Kim SK, Cho KH, Lee J, Lee YS, Kim J, Ha SW, Kim EG, Kim DE, Kang DW, Kwon SU, Yu KH, Lee BC. Risk factors and stroke mechanisms in atherosclerotic stroke: intracranial compared with extracranial and anterior compared with posterior circulation disease. Stroke. 2012;43(12):3313-3318.

31. Lei C, Wu B, Liu M, Chen Y. Risk factors and clinical outcomes associated with intracranial and extracranial atherosclerotic stenosis acute ischemic stroke. J Stroke Cerebrovasc Dis. 2014;23(5):1112-1117.

32. Takahashi W, Ohnuki T, Ohnuki Y, Kawada S, Takagi S. The role of high-sensitivity C-reactive protein in asymptomatic intra- and extracranial large artery diseases. Cerebrovasc Dis. 2008;26(5):549-555.

33. Bang OY, Lee PH, Yoon SR, Lee MA, Joo IS, Huh K. Inflammatory markers, rather than conventional risk factors, are different between carotid and MCA atherosclerosis. J Neurol Neurosurg Psychiatry. 2005;76(8):1128-1134.

34. da Silva A, Caldas A, Hermsdorff H, Bersch-Ferreira Â, Torreglosa C, Weber B, Bressan J. Triglycerideglucose index is associated with symptomatic coronary artery disease in patients in secondary care. Cardiovascular diabetology. 2019;18(1):89.

\section{Figures}




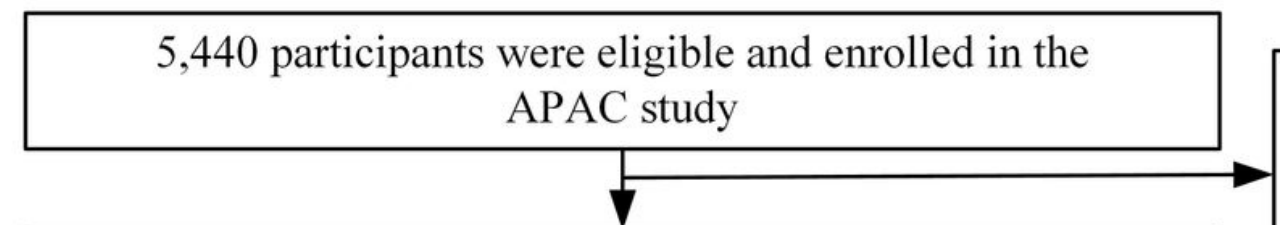

5,381 participants were eligible and enrolled in the crosssectional analysis
Excluded:

59 participants with missing data on TG, FBG and vascular examination results
Excluded:

712 participants with ICAS at baseline;

1,222 participants without ICAS measurement at 2012

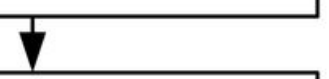

3,447 participants were enrolled for the analysis of incident ICAS
Excluded:

2,843 participants with

ECAS at baseline;

685 participants without

ECAS measurement at 2012

were excluded

1,853 participants were enrolled for the analysis of incident ECAS

\section{Figure 1}

The flowchart of the study Abbreviations: APAC, Asymptomatic Polyvascular Abnormalities Community; ECAS, extracranial carotid stenosis; ICAS, intracranial arterial stenosis; FBG, fasting blood glucose; TG, triglyceride 


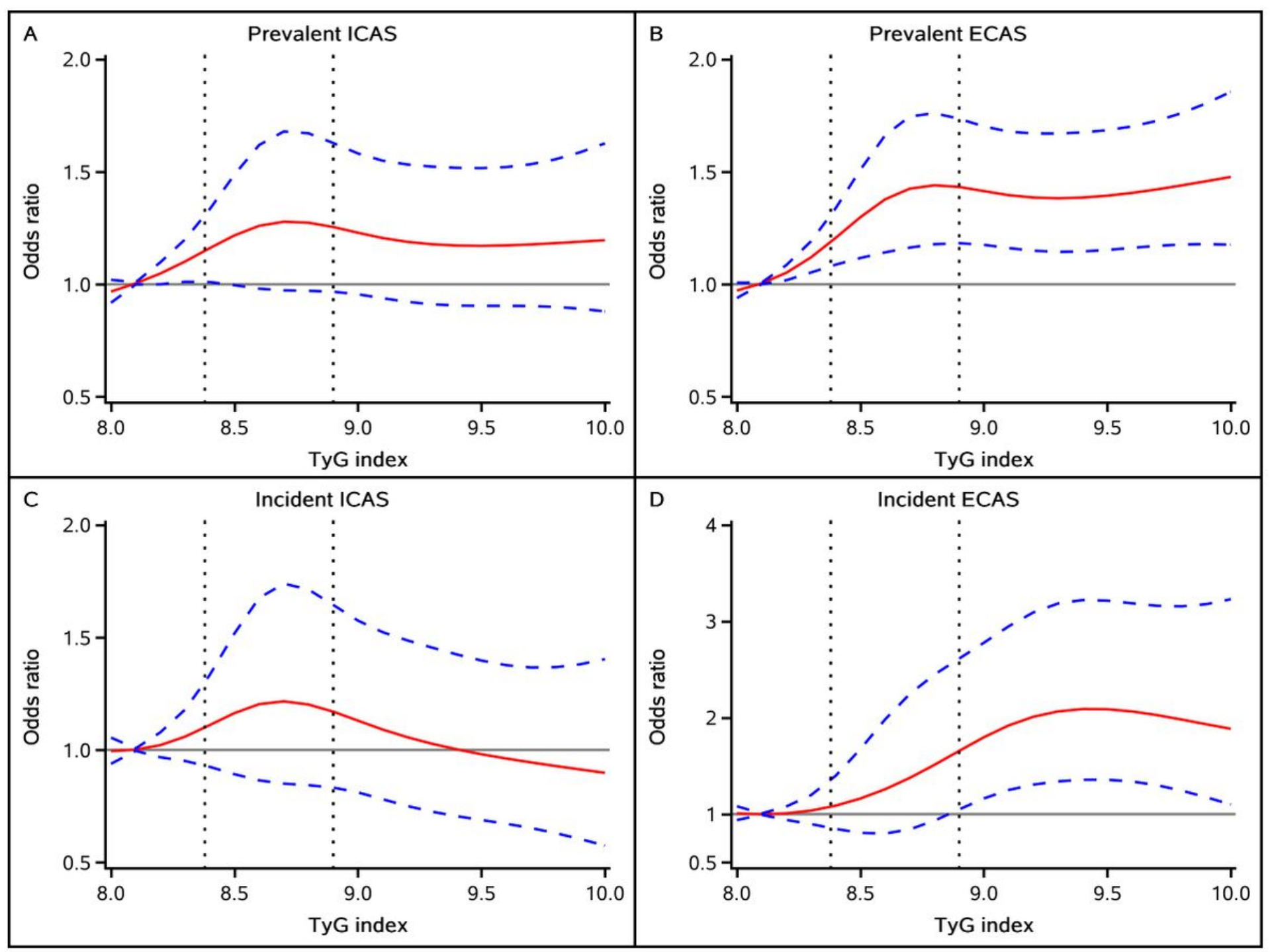

Figure 2

Multivariable-adjusted association of the TyG index with ICAS and ECAS based on restricted cubic spines with 5 knots at 5th, 25th, 50th, 75th, and 95th percentiles of TyG index. A-B: outcomes in the crosssectional analysis; C-D; outcomes in the longitudinal cohort analysis Abbreviations: ECAS, extracranial carotid stenosis; ICAS, intracranial arterial stenosis; TyG index, triglyceride-glucose index. Adjusted for body mass index, education, income, physical activity, smoking status, drinking status, history of hypertension, diabetes, dyslipidemia, antihypertensive agents, antidiabetic agents, lipid-lowering agents, high-density lipoprotein cholesterol, low-density lipoprotein cholesterol, high-sensitivity C-reactive protein.

\section{Supplementary Files}

This is a list of supplementary files associated with this preprint. Click to download.

- SupplementalMaterials.docx 